Witko, Christopher, and Adam J. Newmark. 2005. "Business Mobilization and Public Policy in the U.S. States." Social Science Quarterly (Blackwell Publishing Limited) 86, no. 2: 356-367. DOI: 10.1111/j.0038-4941.2005.00307.x

\title{
Business Mobilization and Public Policy in the U.S. States.
}

\author{
Christopher Witko and Adam J. Newmark
}

\begin{abstract}
The goal of this study is to examine how the political mobilization of business interests influences aggregate public policy outputs in the states. We examine the relationship between business mobilization and general state policy liberalism, as well as policy that we term state"business policy climate."We construct a measure of the"business policy climate" from a number of tax and regulatory indicators in the states and examine whether business influences it and policy liberalism using ordinary least squares regression. The analysis shows that business mobilization does not influence general policy liberalism but is a significant influence on a state's business policy climate. Specifically, the dominance of a state's campaign finance system by business interests makes policy more favorable toward business. The extent of business mobilization in a state is an important influence on public policy outputs but is constrained by the activities of other political actors such as unions.
\end{abstract}

\section{ARTICLE}

Scholars have studied the determinants of state public policy for decades. In their seminal work on state politics, Erikson, Wright, and Mclver (1993) observed strong links between public opinion and policy in the states. However, as Gray et al. (2002) point out, it is necessary to consider interest groups for a complete understanding of how political actors influence policy in the U.S. states. Since it is often argued that business interests have advantages over others, their influence on state policy deserves careful 
scrutiny. Yet, the relationship between the mobilization of the business community and aggregate public policy outputs in the U.S. states has received surprisingly little empirical attention. Furthermore, given their variation in interest-group strength, ideology, and policy, the states offer an ideal venue in which to examine broad questions of business influence. We consider whether the political mobilization of business influences policy liberalism and policy of more central concern to the business community, which we call state "business policy climate."

\section{Business Influence in the States}

Business interests have advantages in overcoming the collective action problems plaguing all interests mobilizing for political activity (Olson, 1965). Consequently, at both national and state levels, interest systems are numerically dominated by economic interests (Schlozman, 1984; Gray and Lowery, 1996). There is some disagreement about how this numerical dominance translates into influence on public policy. Pluralist or neopluralist theories expect that business interests are able to influence government policy by providing campaign assistance to politicians, or through the lobbying process, but this influence is contingent on factors such as the level of public scrutiny, countermobilization by other interests, and the preferences of elected public officials (McFarland, 2004). In contrast, structural theorists argue that business has a "privileged position" among societal interests in a capitalist system, where elected officials are dependent on business to spur the economic growth necessary to ensure reelection (Lindblom, 1977). Both perspectives acknowledge that business interests will often wield influence on public policy. As Mitchell (1997) argues, it is reasonable to assume that elected officials want to keep business happy both because they rely on these businesses to create economic growth and because of the more direct assistance and/or pressure that the businesses bring to bear. Not surprisingly, scholars have found that businesses do influence aggregate policy outputs (Quinn and Shapiro, 1991; Inclan, Quinn, and Shapiro, 2001). However, business does not always triumph because its goals are often opposed by other actors, such as unions or the public (Radcliff and Saiz, 1998; Smith, 2000).

The extent to which relevant actors are organized varies a great deal across the states, and this has important policy implications. For example, Hill and Leighley (1992) find that states with a greater mobilization of poor voters demonstrate more generous welfare policies and Radcliff and Saiz (1998) find that the degree of labor union organization affects state spending on a variety of programs, as well as policy 
liberalism. The examination of business mobilization and influence in the states has generally been limited to single policy areas such as environmental policy (Potoski and Woods, 2002). In one exception, Gray et al. (2002) find tentative support for the idea that states with more politically active economic interests have less liberal policy. Accordingly, we expect business to be an important influence on aggregate state policy, but business influence should also be constrained by the actions of other political actors.

There are strong incentives for elected state officials to accede to business. As structuralists note, politicians need business investment and the resulting economic growth to create favorable electoral conditions, making them especially responsive (Lindblom, 1977). However, this dynamic is essentially constant across states and is therefore of limited utility in explaining cross-sectional differences in policy. Therefore, we focus on how the variation in the effective marshalling of business resources into the political process may explain differences in policy. Since business interests have abundant resources, they have mostly relied on "insider tactics such as lobbying lawmakers directly." Therefore, the national-level studies usually examine the aggregate influence of PAC contributions and lobbying expenditures on government policy (Inclan, Quinn, and Shapiro, 2001; Quinn and Shapiro, 1991; Smith, 2000). Campaign contributions and lobbying should also be important indicators of business mobilization in the states. If these tactics are effective, states with a greater proportion of campaign contributions from business, and greater business density in the lobbying community, should demonstrate more conservative and pro-business policy.

Several state-level political actors constrain the influence of business interests, however. Unions have an agenda that often runs directly counter to business interests by focusing on policy that is relevant to union members and the working class more broadly (Radcliff and Saiz, 1998). Like business, unions contribute money to candidates, but unlike business, labor's political strength is also linked to the number of members that can be turned out on election day.

The preferences and deeply held beliefs of the public and political elites will also constrain or foster business interests. Elazar (1984) noted that individualistic cultures may utilize policies to facilitate the interests of businesses, and traditionalistic cultures may take a laissez-faire approach to economics (implying limited business regulation). In contrast, moralistic cultures should be more willing to use the political process to counter the power of economic interests and promote the public good. In addition, 
public and government ideology clearly have important influences on aggregate policy outcomes (Erikson, Wright, and Mclver, 1993). Liberal ideology advocates more direct government involvement in the economy and a more aggressive mitigation of the effects of unfettered capitalism. As such, liberal states should demonstrate policy that is less favorable to business. The public's influence should be greatest on salient, gut-reactiontype issues like gun control, abortion, and welfare, however. In contrast, the greater complexity of taxation and regulation (policies more relevant to business) may mute the opinion-policy linkage.

\section{When Will Business Matter?}

We consider two questions in the analysis below. Does the dominance of a state's interest-group system by business interests make policy in that state more conservative, after controlling for factors like government and citizen ideology, political culture, and the mobilization of other interest organizations? Or, is business influence limited to issues centering on the core interests of the business community?

Scholars have argued that business power has a conservative influence on policy (Lindblom, 1977), but business is motivated by profit and is consequently most concerned with policies that have a clear influence on the bottom line. As a result, we might expect that business mobilization will have little influence on the type of composite policy liberalism considered by Erikson, Wright, and Mclver (1993). Gray et al. (2002) argue that the dominance of business interests may mute state policy liberalism through a crowding effect, however. For example, the demands of abortion rights or poverty advocates may be muted because politicians, with limited time and resources, cater primarily to economic interests. These scholars tentatively conclude that politicians are less responsive to the public in systems more heavily dominated by economic interests. Even without endorsing the crowding argument, business dominance may indirectly make state policy more conservative. Although business interests are not necessarily adamant about small government or limited welfare and health-care spending, successful demands for low taxes will often preclude the existence of generous social programs or a large public sector.

Despite these real possibilities, we expect that business influence (even indirect) should be most highly constrained on policies that define composite policy liberalism including 
policies like abortion, gun control, and welfare eligibility. Wright, Erikson, and Mclver (1993) find strong links between public opinion and policy on these issues. The relationship between opinion and policy on these issues is probably heightened because they are of concern to political parties, news media, and political activists. When public preferences are known and relatively intense, politicians will usually respond, limiting the influence of business (Smith, 2000). Additionally, politicians are likely to have their own, well-formed preferences on these ideological issues. Finally, labor unions typically have broad policy goals (Radcliff and Saiz, 1998), so we expect them to be highly active, limiting business influence on these issues.

Businesses have a greater direct stake in policies that are directly relevant to the bottom line, such as taxation and regulation. Different business sectors have divergent political agendas, but they will be unified in opposing higher taxes and greater regulation. Nonetheless, liberal politicians may be conflicted over whether to meet business demands or follow their personal ideology, with liberal public opinion further constraining policy choices. Furthermore, a state's political culture should be an important determinant of its approach to business politics, with moralistic cultures being more willing to use the government to limit business power. Finally, many of these policies will also arouse the interest of unions, thus also constraining business influence.

Despite this conflict, there is reason to believe that business will fare better on these issues. First, since taxation and regulation encompass the core interests of nearly all businesses, we can expect more pressure from the business community on policymakers. Second, since issues of taxation and regulation are less salient to the public than issues like abortion, gun control, and welfare, elected officials may have more independence from public preferences. The appropriate level of government taxation and regulation can easily eclipse the knowledge and interest of the public. Therefore, unlike composite policy liberalism, we expect a clear relationship between business mobilization and business policy climate. Given their broader interests, we expect that unions will influence both sets of policies. Ideology (both public and government) should have a stronger influence on composite policy liberalism than on business policy. State political culture should not influence composite liberalism, but should influence business policy, with more traditionalistic cultures demonstrating business-friendly policy. 1 


\section{Data and Methods}

To examine business influence on general policy liberalism (our first dependent variable), we use an updated version of Erikson, Wright, and Mclver's policy liberalism created by Gray et al. (2002) that includes: welfare eligibility and activities under TANF, right-to-work laws, abortion regulation, gun control, and tax structure progressivity. Like Erikson, Wright, and Mclver's (1993) measure, components were standardized and summed to create the index. The index ranged from -4.76 to 6.93 , with a mean of -0.07 $(\mathrm{SD}=3.13)$. The index correlates with Erikson, Wright, and Mclver's at 0.75 and has a Cronbach's alpha of 0.63 .

The second portion of the analysis will examine business influence on state business policy climate, which is an aggregate policy measure comprised of tax and regulatory indicators. Here, we are not attempting to comprehensively measure a state's business climate, but rather to develop a measure based on policies at the core of the political interests of business. As such, our measure reflects only one portion of a state's business climate. 2 The measure of "business policy climate" consists of nine policy indicators. These are: (1) the corporate alternative minimum tax, (2) the top corporate tax rate, (3) the percentage of revenue from corporate taxation, (4) the state's tax limitation status, (5) the number of pro-business legal reforms statutes, (6) the prevailing wage in the state, (7) the state's minimum wage, (8) new-source pollution regulations, and (9) air-quality regulations (see Table 1). Some indicators apply more directly to the interests of specific economic sectors, but taken together, they measure policy that concerns most of the business community. Furthermore, in addition to reflecting specific policy decisions, this index represents a state's aggregate approach to taxation and regulation, whereby states that heavily regulate labor and environmental practices are more likely to regulate other business activities.

\section{TABLE 1}

Factor Loadings for Business Climate Variables

Variable

Corporate alternative minimum tax
Data Source

Tax Foundation website
Factor

Loading

0.48 
Top corporate tax rate

Percentage of revenue from corporate taxation

Tax limitation status

Pro-business legal reforms

Prevailing wage

Minimum wage

New-source pollution regulations

Air-quality regulations

Eigenvalue

Cronbach's alpha
Tax Foundation website

0.35

Federation of Tax Administrators'

0.32 website

Tax Foundation website

0.35

American Tort Reform Association website

U.S. Department of Labor website

0.53

U.S. Department of Labor website

0.39

Book of the States

0.50

Book of the States

0.32

1.73

0.65

Like Erikson, Wright, and Mclver (1993), we standardized and summed all components to create the measure, with higher scores indicating a more favorable business policy climate. The business policy index ranges from -10.64 to 11.96 , with a mean of 0.0 and standard deviation of 4.62 . With components covering several distinct policies, we might expect that this measure does not adequately assess a single underlying policy dimension. However, confirmatory factor analysis demonstrated that these policies do load on a single factor with all coefficients above 0.30 (see Table 1 for factor loadings and data sources). The single factor does not explain a large portion of the total variance of these nine variables (approximately 20 percent), but this is not entirely surprising given the diversity of components. Finally, the measure produces a Cronbach's alpha of 0.65 , which is roughly equivalent to the liberalism measure's reliability (though both are slightly less than 0.70 , which would indicate high reliability). 3 Though created for different purposes, this measure correlates with broader business policy climate indices in the expected direction 4 and is also negatively correlated $(-0.66)$ with Gray et al.'s (2002) update of composite liberalism. For both dependent variables, policy was measured in the year 2000.

Before we turn to the analysis, Table 2 shows the rankings and scores of the most and least favorable tax and regulatory business policy climates in the states. The scores ranged from a high of 11.96 in Mississippi to a low of -10.64 in Alaska, with a mean of 0 and standard deviation of 4.62. The states are ordered so that the number-one ranking state, Mississippi, has the most favorable business policy climate, followed by Nevada, South Dakota, Louisiana, and Arizona. At the other end of the rankings, Alaska had the least favorable business policy climate, followed by Maine and Minnesota. The business 
policy climate is in some ways related to liberalism, but it is also clearly measuring something different. For example, some relatively conservative states, such as Nebraska, lowa, and Montana, appear relatively unfavorable to business interests. Perhaps surprisingly, large and dynamic economies that lead the nation in wealth production, such as New York and California, receive very low scores, reflecting the more limited focus of our business policy climate measure. 5 Although these states are important in the national and even global economies, their success has much to do with nonpolicy factors, and they do have high corporate taxes, high wages, and relatively strict regulations. Our unidimensional measure is also not designed to account for states that may be favorable to particular economic sectors. For example, Delaware provides an excellent tax and regulatory environment for financial institutions but this is just one business sector, and we are concerned with those policies important to the average business in a given state.

TABLE 2

State Business Climate Rankings and Scores

\begin{tabular}{lllll}
\hline \multicolumn{4}{l}{ Rank State Score } & \multicolumn{3}{l}{ Rank State Score } \\
\hline 1 & MS & 11.9574826 & PA & 0.165084 \\
2 & NV & 7.37895527 & MD & 0.149995 \\
3 & SD & 6.80999428 & NM & -0.50712 \\
4 & LA & 6.80368729 & NH & -0.92906 \\
5 & AZ & 6.51022330 & WI & -0.97284 \\
6 & CO & 6.46277631 & KY & -1.05656 \\
7 & OK & 6.37891332 & DE & -1.45441 \\
8 & SC & 4.77135533 & IL & -1.61219 \\
9 & AL & 4.70411334 & NJ & -1.67785 \\
10 & VA & 3.03253935 & OR & -1.85299 \\
11 & TX & 2.71807136 & WA & -2.24678 \\
12 & UT & 2.68121237 & MA & -2.46548 \\
13 & KS & 2.30690238 & ND & -2.60898 \\
14 & MO & 2.30174839 & HI & -2.95108 \\
15 & FL & 2.15517840 & MT & -2.96248 \\
16 & GA & 1.72657941 & IA & -3.00357 \\
17 & ID & 1.54053442 & NE & -3.13098 \\
18 & TN & 1.53316543 & RI & -4.37246
\end{tabular}




\begin{tabular}{lllll}
19 & AR & 1.51189144 & CT & -4.39796 \\
20 & OH & 0.86692445 & VT & -4.73919 \\
21 & MI & 0.74862546 & CA & -5.20599 \\
22 & NC & 0.58431247 & NY & -7.85591 \\
23 & WV & 0.36252148 & MN & -10.0226 \\
24 & WY & 0.32831149 & ME & -10.0769 \\
25 & IN & 0.24749250 & AK & -10.6353 \\
\hline
\end{tabular}

To assess business influence on both sets of policy, we regressed the dependent variables on business lobbying registration and business campaign contribution variables, as well as union campaign contributions and union membership, government and public ideology, and state political culture. As noted above, business primarily influences policy by lobbying and/or contributing money to politicians. Therefore, we include measures of both. We use Gray and Lowery's registration data on all organizations registered to lobby to construct a business density measure for each state in 1999. We included the following sectors: agriculture, banking, communications, construction, health, hotel, insurance, manufacturing, small businesses, sports, transportation, and utilities. Business density is the total number of organizations and firms registered with the state in the above sectors (Gray and Lowery, 1996). Business registrants ranged from 129 to 1,177 with a mean of 431 and standard deviation of 269.06.

The campaign contribution measure was the percentage of all campaign contributions from PACs and individuals affiliated with business interests (specific firms and trade associations) from 1996-2000. These data were obtained from the Institute on Money in State Politics' website 〈http://www.followthemoney.org〉. We use the annual average of contributions between 1996 and 2000 to minimize single-year spikes. Business contribution percentages ranged from 11.2 to 56.2 , with a mean of 35.22 percent (standard deviation of 9.6).

We also use two variables to measure labor's mobilization. Given their grassroots nature, density (or percentage of union members) in the workforce is a better measure of their potential influence than lobbying density. We averaged density for the years 1990 and 2000 in each state, resulting in a measure ranging from 4.9 to 30.65 , with a 
mean of 15.55 and standard deviation of 6.28. The union campaign contribution measure is analogous to the one discussed above. This measure ranged from 1.1 to 55.3 with an average of 17.1 (standard deviation of 11 ).

We use Berry et al.'s (1998) measures to control for public and government ideology, which are each averaged for the period 1996-1999. Government ideology ranges from 4.5 to 94.58 with a mean of 43.06 and standard deviation of 24.30. Citizen ideology ranges from 18.07 to 82.93 with a mean of 47.66 and a standard deviation of 14.04 . We also control for political culture using Koven and Mausolff's (2002) update of Sharkansky's (1969) quantification of Elazar's (1984) categorization of the states.6 Since moralistic states score lower on this measure, we expect a positive relationship between culture and business policy climate.

\section{Results}

The first column of Table 3 presents the analysis examining the relationship between our independent variables and general policy liberalism. Only 48 states are included because, following Erikson, Wright, and Mclver (1993), Alaska and Hawaii were excluded due to missing data. The R2 statistic for this model was 0.58 , and the results are unsurprising. As we can see, states with more liberal citizens and states with a more liberal government demonstrate more liberal public policy; both ideology coefficients were statistically significant and in the expected, positive direction. Supporting the conclusions of Radcliff and Saiz (1998), states with greater union membership exhibit more liberal policy, even after controlling for business influence. The coefficient for union membership was positive and statistically significant, but the coefficient for union campaign contributions was not, indicating that union influence probably lies primarily in labor's potential to deliver votes, rather than to finance campaigns. Neither measure of business mobilization was significant in this model, nor was state political culture. This indicates that high levels of business mobilization do not make aggregate state policy of this type more conservative. 
TABLE 3

The Influence of Business Interests on State Policy Liberalism and State Business Policy Climate

\begin{tabular}{|c|c|c|}
\hline Independent Variables & Policy Liberalism & Business Policy Climate \\
\hline \multirow[t]{2}{*}{ Government ideology } & $0.040^{*}$ & $-0.062^{*}$ \\
\hline & $(0.018)$ & $(0.028)$ \\
\hline \multirow[t]{2}{*}{ Citizen/public opinion liberalism } & $0.071^{*}$ & 0.006 \\
\hline & $(0.037)$ & $(0.051)$ \\
\hline \multirow[t]{2}{*}{ Union membership } & $0.129^{*}$ & $-0.243^{* *}$ \\
\hline & $(0.073)$ & $(0.097)$ \\
\hline \multirow[t]{2}{*}{ Union contributions } & -0.142 & 0.005 \\
\hline & $(0.117)$ & $(0.177)$ \\
\hline \multirow[t]{2}{*}{ Business registrants } & 0.001 & -0.000 \\
\hline & $(0.001)$ & $(0.001)$ \\
\hline \multirow[t]{2}{*}{ Business contributions } & -0.038 & $0.128^{*}$ \\
\hline & $(0.039)$ & $(0.058)$ \\
\hline \multirow[t]{2}{*}{ Political culture } & -0.276 & $0.584^{*}$ \\
\hline & $(0.180)$ & $(0.257)$ \\
\hline $\mathrm{R}^{2}$ & 0.58 & 0.55 \\
\hline $\mathrm{N}$ & 48 & 50 \\
\hline \multicolumn{3}{|c|}{$\begin{array}{l}\text { OLS estimates. Unstandardized coefficients with standard errors in parentheses; }{ }^{*} \mathrm{p}<0.05 \text {; } \\
\mathrm{p}<0.01 \text { (one-tailed). }\end{array}$} \\
\hline
\end{tabular}

The second column of Table 3 presents the results of the same model but with business policy climate as the dependent variable. Again, higher values on our business policy index indicate greater favorability toward business in tax and regulatory policies. This model explains a substantial portion of the variance in business policy climate $(R 2=0.55)$. Although we did expect a somewhat weaker relationship between citizen ideology and the business policy climate, the analysis indicates that there is no significant relationship at all. Indeed, on this set of policies it does seem that the opinion-policy linkage is weakened or nonexistent once we control for other factors. The independent preferences of state policymakers did influence this set of policies, however, with more liberal officials enacting policy less favorable to business. The 
divergent influence of public and government ideology may stem from the greater complexity of taxation and regulatory policies compared to the policies comprising composite policy liberalism. Although state political culture has no impact on general policy liberalism, it does influence state business policy climate. States with more traditionalistic cultures have a more favorable business policy climate compared to moralistic cultures. As in the previous model, labor union membership influences policy, but contributions do not. Thus, high rates of union membership as opposed to campaign contributions seem to be the important resource that enables labor to constrain business in the states.

Turning to the business mobilization variables, the empirical results affirm some of our theoretical expectations. Lobbying mobilization did not influence the business policy climate, but business contributions were statistically significant and positive influences on it. Furthermore, at the extremes, business contributions can have a large influence on policy. For example, if we compare Louisiana (56.2 percent of contributions from business) to Vermont (11.2 percent), we see a large 5.6 point increase on our business policy climate measure, with other factors constant. Contributions may be a better indicator of business mobilization than lobbying density because the contribution variable represents a clearer investment of resources.

At first glance, the results of this analysis indicate that the narrower area of policy that we call state business policy climate is largely the domain of interest groups, with little citizen input or control. However, labor unions advocate on behalf of workers in general, and not just union members, and to that extent citizens are represented in these policy areas. The impact of union membership was quite substantial, and it is statistically significant at the 0.01 level in the expected, negative direction. Thus, with other factors constant, we can expect a 6.3 point decrease in business favorability comparing the least unionized state, South Carolina, to New York, which has the highest unionization rate. Although business interests clearly have important financial resources, unions have members who can sway elections and this appears to give unions some leverage. The consistent influence of unions on both sets of policy underscores the importance of labor unions as a political force in the states and also highlights the important policy consequences of decreasing unionization in the United States.

\section{Conclusion}


This study confirms the pluralist mantra that mobilization is critical to an interest group's success in the political process. The extent of business mobilization, along with the mix of countervailing forces present at the state level, explains variation in certain types of policy across the states. The public, elected officials, and organized labor are the primary influences on composite policy liberalism. Business mobilization influences the state business policy climate, with greater campaign financing by business leading to more favorable outcomes. On neither policy domain is there evidence indicating monolithic and unchallenged business influence. Instead, it appears that even on state business policy climate, business influence is constrained. Although businesses try to utilize their resource advantage over other groups, unions appear to partially balance this financial advantage with their broader membership base. Finally, as the conventional wisdom suggests, campaign contributions are an important source of business power in the states. Politicians who are more reliant on business interests for their reelection funding are more likely to enact pro-business policy. Considering the largely ineffective state campaign finance regulations in tandem with declining unionization rates in most states, if anything, business should become more powerful in the near future.

\section{Footnotes}

1 Radcliff and Saiz (1998) include political culture in their model but do not present results for this variable. Consequently, we assume it was not a significant influence on policy liberalism.

2 When politicians and business leaders use the term business climate they are referring to dozens of attributes affecting the profitability of business enterprises in a given state. Components of a state's business environment like proximity to ports and natural resources were ignored in this study because they are not subject to political manipulation, and education and training policies were omitted because they are not relevant to many industries. Education spending, for example, is of greater concern to high-tech firms compared to agricultural or manufacturing firms. Furthermore, separate analysis demonstrated that these investment policies generally do not correlate with the taxation and regulation of business, while also not clearly constituting an entirely separate dimension of policy. Nor did we consider factors like electricity costs that are only partially (and not primarily) determined by government policy. Initially, 33 business climate indicators were collected from a number of sources, including other business climate indices created by advocacy organizations or think tanks. Examples were the 
Tax Foundation, the Small Business Survival Committee, the Beacon Hill Institute, the Progressive Policy Institute, the Corporation for Enterprise Development, and the Economic Freedom Index created by Byers, McCormick, and Yandle (1999). Once this initial set of indicators was collected, exploratory factor analysis was used to determine which variables were empirically closely related. We expected to see a few clear policy dimensions (ideally, separate regulatory, tax, and infrastructure investment dimensions). Unexpectedly, rather than suggesting a few distinct policy dimensions, only one clear factor emerged, which was the basis for our measure of business policy climate. Though the results of this process countered our initial expectations, we believe that the resulting policy index accurately reflects a state's general regulatory and tax policy stance toward the business community.

3 The diversity of business interests demands the inclusion of a wide array of policies for a meaningful measure. Therefore, greater interitem correlations and a higher alpha would be difficult to achieve.

4 The measure is positively correlated with climate measures created by the Tax Foundation (0.15), the Small Business Survival Committee (0.26), the Beacon Hill Institute (0.40), and Byars, McCormick, and Yandle's measure of economic freedom (0.31).

5 Many factors influence state business climate, including historical development and settlement patterns, which are obviously outside the scope of this article. New York's important role in business and finance is driven, in part, by the decisions of many firms to locate in and around Wall Street over the past century or more. Furthermore, many states are favorable to certain industries because of a particular environment or natural resources possessed by the states (i.e., mining in Pennsylvania or the citrus industry in Florida).

6 Sharkansky employed a nine-point scale coding pure moralistic states as 1, pure individualistic states as 5 , and pure traditionalistic states as 9 , with mixed states arrayed between these scores. Koven and Mausolff (2002) did not include Alaska, but since it is generally considered an individualistic political culture, we coded it as a 5 . 


\section{References}

Berry, William D., Evan J. Ringquist, Richard C. Fording, and Russel L. Hanson. 1998. "Measuring Citizen and Government Ideology in the American States, 196093."American Journal of Political Science 42 (1): 327-48.

Byers, John, Bobby McCormick, and Bruce Yandle. 1999. Economic Freedom in America's 50 States: A 1999 Analysis. Center for Policy and Legal Studies, Department of Economics, Clemson University. Available at 〈http://freedom.clemson.edu〉.

Elazar, Daniel J. 1984. American Federalism: A View from the States. New York: Harper and Row.

Erikson, Robert S., Gerald C. Wright, and John P. Mclver. 1993. Statehouse Democracy: Public Opinion and Policy in the American States. New York: Cambridge Press.

Gray, Virginia, and David Lowery. 1996. The Population Ecology of Interest Representation: Lobbying Communities in the American States. Ann Arbor, Ml: University of Michigan Press.

Gray, Virginia, David Lowery, Matthew Fellowes, and Andrea McAtee. 2002. "The Opinion-Policy Linkage in the American States: Professional Legislatures, Organized Interests, and Policy Responsiveness."Paper presented at the Second Annual State Politics and Policy Conference. Milwaukee, WI.

Hill, Kim, and Jan Leighley. 1992. "The Policy Consequences of Bias in State Electorates."American Journal of Political Science 36: 351-65.

Inclan, Carl, Dennis P. Quinn, and Robert Y. Shapiro. 2001. "Origins and Consequences of Changes in U.S. Corporate Taxation, 1981-1998."American Journal of Political Science 45 (1): 179-201.

Koven, S. G., and C. Mausolff. 2002. "The Influence of Political Culture on State Budgets: Another Look at Elazar's Formulation."American Review of Public Administration, 32 (1): 66-77

Lindblom, Charles. 1977. Politics and Markets. New York: Basic Books. 
McFarland, Andrew S. 2004. Neopluralism: The Evolution of Political Process Theory. Lawrence, KS: University of Kansas Press.

Mitchell, Neil J. 1997. The Conspicuous Corporation: Business, Public Policy and Representative Democracy. Ann Arbor, MI: University of Michigan Press.

Olson, Mancur. 1965. The Logic of Collective Action: Public Goods and the Theory of Groups. Cambridge: Harvard University Press.

Potoski, Matthew, and Neal D. Woods. 2002. "Dimensions of State Environmental Policies: Air Pollution Regulation in the United States."Policy Studies Journal 30 (2): 208-26.

Quinn, Dennis P., and Robert Y. Shapiro. 1991. "Business Political Power: The Case of Taxation."American Political Science Review 85: 851-74.

Radcliff, Benjamin, and Martin Saiz. 1998. "Labor Organization and Public Policy in the American States."Journal of Politics 60 (1): 113-25.

Schlozman, Kay Lehman. 1984. "What Accent the Heavenly Chorus? Political Equality and the American Pressure System."Journal of Politics 45: 351-77.

Sharkansky, Ira. 1969. "The Utility of Elazar's Political Culture."Polity 2: 66-83.

Smith, Mark A. 2000. American Business and Political Power. Chicago, IL: Chicago University Press. 